\title{
Impact of Salicylic Acid Treatments on Storage Quality of Guava Fruits cv. Lalit during Storage
}

\author{
Janagam Venu Madhav ${ }^{1 *}$, Shruti Sethi ${ }^{1}$, R.R. Sharma ${ }^{1}$ and A. Nagaraja ${ }^{2}$ \\ ${ }^{1}$ Division of Food Science and Postharvest Technology, ${ }^{2}$ Division of Fruits and Horticultural \\ Technology, ICAR-Indian Agricultural Research Institute, \\ New Delhi, New Delhi - 110012, India \\ *Corresponding author
}

A B S T R A C T

\begin{tabular}{|c|}
\hline Keywords \\
\hline $\begin{array}{l}\text { Guava, Weight loss, } \\
\text { Respiration rate, Total } \\
\text { phenolics, Ascorbic acid }\end{array}$ \\
\hline Article Info \\
\hline $\begin{array}{l}\text { Accepted: } \\
16 \text { August } 2018 \\
\text { Available Online: } \\
10 \text { September } 2018\end{array}$ \\
\hline
\end{tabular}

\section{Introduction}

Guava (Psidium guajava L.) is widely cultivated fruit crop in tropical and subtropical countries. In India, it is the fifth important fruit with a production of 3.82 million MT from an area of 0.26 million ha (NHB, 201617). It is consumed fresh or processed into juices, purees, jams, and jellies. The fruits are very nutritious and rich in carotenoids, phenols, vitamins $\mathrm{A}$ and $\mathrm{C}$, and dietary fibers, and are known for their high antioxidant activity (Bashir and Abu-Goukh, 2003). Guava is a climacteric fruit which ripens rapidly and is highly perishable and its shelf- life is only 2 to 3 days at the room temperature (Bassetto et al., 2005). The delicate nature, short postharvest life, and susceptibility to chilling injury and diseases, limits the potential for commercialisation of this important fruit. Researchers have worked on some expensive interventions such as the use of irradiation, controlled atmospheric storage, modified atmosphere packaging and application of fungicides to extend the storage life of guava (Singh and Pal, 2008; Antala et al., 2015) but there is an urgent need to develop safe and affordable postharvest practices to increase its life while maintain the quality. In the recent years, several generally 
regarded as safe (GRAS) compounds have been attempted in fruit crops, of which salicylic acid has given fruitful results (Asghari and Aghdam, 2010). Salicylic acid, accepted as a safe and natural chemical compound for postharvest application on fruits has been used to delay the ripening and softening, reduce lipid peroxidation and chilling injury in fruits (Zhang et al., 2003; Barman and Asrey, 2014). Hence, we investigated the effect of postharvest application of salicylic acid (SA) and 5sulfosalicylic acid (SSA) (a derivative of SA) on different quality attributes of guava fruits.

\section{Materials and Methods}

Fully mature guava fruits of cv. Lalit were harvested from the orchard of Division of Fruits and Horticultural Technology, IARI, New Delhi, in the morning hours and immediately brought to the laboratory. Fruits of uniform size and maturity and without wounds or blemishes were selected and immersed in the 1 and $2 \mathrm{mM}$ solution each of salicylic acid (SA) and 5-sulfosalicylic acid (SSA) for 5 minutes. The fruits of the control lot were dipped in distilled water only. After treatment, fruits were air-dried and stored at $10^{\circ} \mathrm{C}$ temperature and $85 \pm 5 \% \mathrm{RH}$. After storage, fruits were transferred to ambient conditions $\left(20 \pm 2^{\circ} \mathrm{C}\right)$ for shelf life simulation for three days every time and observations were recorded up to $12+3$ days.

Weight loss percentage was measured by subtracting the initial sample weight from the final weight at a particular time interval. Fruit firmness was measured using an InstronUniversal Testing Machine (Model: TA + Di, Stable Microsystems, UK) and expressed as Newton (N). Peel colour of the fruits was measured by Hunter Colour Lab Scan XE and the CIE L, a, b colour scale. Respiration rate of the fruits was measured by the static headspace technique using an auto gas analyser (Checkmate $9900 \quad \mathrm{O}_{2} / \mathrm{CO}_{2}, \quad \mathrm{PBI}$ Dansensor, Denmark) and expressed as $\mathrm{mL}$ $\mathrm{CO}_{2} \mathrm{~kg}^{-1}$ fresh weight $\mathrm{h}^{-1}$ (Singh and Pal, 2008). Ethylene evolution rate was determined by a gas chromatograph (Hewlett Packard 5890 Series II, USA) and expressed in $\mu \mathrm{L}$ ethylene $\mathrm{kg}^{-1} \mathrm{~h}^{-1}$ (Singh and Pal, 2008).

Total soluble solids (TSS) of fruits were estimated using Fisher hand refractometer (0$\left.50^{\circ} \mathrm{B}\right)$ and expressed as degree Brix $\left({ }^{\circ} \mathrm{B}\right)$ at $20^{\circ} \mathrm{C}$. Quantitative determination of ascorbic acid was done by a visual titration method, using 2, 6-dichlorophenolindophenol dye (Rangana, 1999) and expressed as $\mathrm{mg} 100 \mathrm{~g}^{-1}$ of fresh weight. Total phenolic content of the fruit extracts were determined by FC reagent method and expressed as $\mathrm{mg}$ gallic acid equiv/100g (Singleton and Rossi, 1965).

The experiments were laid out in factorial CRD design with each treatment consisting of 120 fruits, replicated thrice. The data so obtained were analysed by following standard procedures and the results were compared from ANOVA by calculating the CD (Panse and Sukhatme, 1984).

\section{Results and Discussion}

Weight loss percentage is an important parameter, which is mainly responsible for quantitative as well as qualitative loss of produce. It is evident from the Figure 1A that PLW, irrespective of treatments increased with the advancement of the storage period. Control showed significantly higher PLW from $3+3$ days of storage that gradually increased with the advancement of storage period. It was observed that SA or SSA significantly prevented the loss in weight of the fruits during the entire storage period up to $12+3$ days. After $12+3$ days of storage, minimum PLW was recorded in fruits treated with $2 \mathrm{mM}$ SA or SSA, while the untreated guava fruits showed the highest weight loss. 
Lower PLW in treated fruits might be due to the effect of salicylic acid in suppressing the metabolic activity with respect to respiration and ethylene evolution. Our results are in line with Han et al., (1997) and Razavi et al., (2014) who have also reported a reduced weight loss in salicylic acid treated apples and peach, respectively.

Reduction in firmness of fruits is a major quality change during ripening. Firmness of guava fruits during storage was found to be significantly influenced by the SA or SSA treatments (Fig. 1B). A gradual decline of fruit firmness was observed with the increase in storage period under all the treatments. Untreated fruits showed a significantly higher loss in firmness as compared to SA or SSA treated fruits. SA or SSA $(2 \mathrm{mM})$ showed higher fruit firmness as compared to other treatments. The retention in firmness of SA or SSA treated fruits may be due to inhibition of cell wall and membrane degrading enzymes such as polygalacturonase, lipoxygenase, cellulase and pectin methyl esterase and also due to lower rate of ethylene production (Khademi and Ershadi, 2013). Earlier, Lo'ay and Khateeb (2011) and Wang et al., (2006) have also reported similar results in guava and peach, respectively.

Hue angle represents green colour at $120^{\circ}$ and yellow colour at $90^{\circ}$ (McGuire, 1992). The change of peel colour from green to yellow in guava fruits is an indicative of fruit ripening. In the present investigation, it was observed that guava fruits treated with SA and SSA at 2 $\mathrm{mM}$ concentration did not turn completely yellow till $9+3$ days of storage whereas untreated fruits turned completely yellow even on $6+3$ days of storage (Fig. 1C). This indicates that postharvest application of SA or SSA has delayed the ripening process of guava fruits significantly, probably through inhibition of ethylene production. These results are supported by work done previously by Lo'ay and El Khateeb (2011) in guava fruits. In untreated fruits, the rate of respiration was observed to increase rapidly with a typical climacteric peak after $3+3$ days of storage. However, the salicylic acid treatments suppressed the respiration rate and also delayed the onset of the respiratory climacteric to $6+3 \& 9+3$ days of storage in 1 and $2 \mathrm{mM} \mathrm{SA}$ or SSA treatments, respectively (Fig. 2A). The reduction in respiration rate in SA or SSA treated fruits may be ascribed to delaying the ripening process as previously reported by Barman and Asrey (2014) in mango and Sahar and Wahab (2015) in apricot.

Different salicylic acid treatments significantly influenced the ethylene production rates of guava fruits during low temperature storage (Fig. 2B). Ethylene evolution increased rapidly in untreated fruits, which achieved a climacteric peak on $3+3$ days of storage. Further, the guava fruits treated with SA or SSA showed climacteric peak of ethylene on $6+3$ and $9+3$ days of storage at 1 and $2 \mathrm{mM}$, respectively. Suppression of ethylene production in fruits treated with SA or SSA may be associated with decreased 1-aminocyclopropane-1carboxylic acid (ACC) synthase (Zhang et al., 2003) and/or ACC oxidase activity (Leslie and Romani, 1988).

Total soluble solids of fruits increased in all the treatments with the advancement in storage period (Fig. 3A). However, untreated fruits showed significantly higher TSS at the end of the storage period as compared to fruits treated with at $2 \mathrm{mM} \mathrm{SA}$ or $2 \mathrm{mM}$ SSA. The increase in TSS can be attributed to the conversion of starch to sugar during ripening of guava. Since SA and SSA might have suppressed the catabolic processes such as respiration rate and ethylene production in treated guava fruits, the treated fruits showed a slow increase in TSS. 
Fig.1 Effect of salicylic acid treatments on A) PLW (\%), B) firmness (N) and C) colour (hue angle) of guava cv. Lalit during storage at $10^{\circ} \mathrm{C}$ followed by transfer to ambient conditions for 3 days ( $\mathrm{T}_{1}$-SA@1 mM, T2-SA @ 2 mM, T 3 -SSA @1 mM, T 4 -SA @ 2 mM and control). Data are the mean $\pm \mathrm{SE}$ of three replicates $(\mathrm{n}=3)$

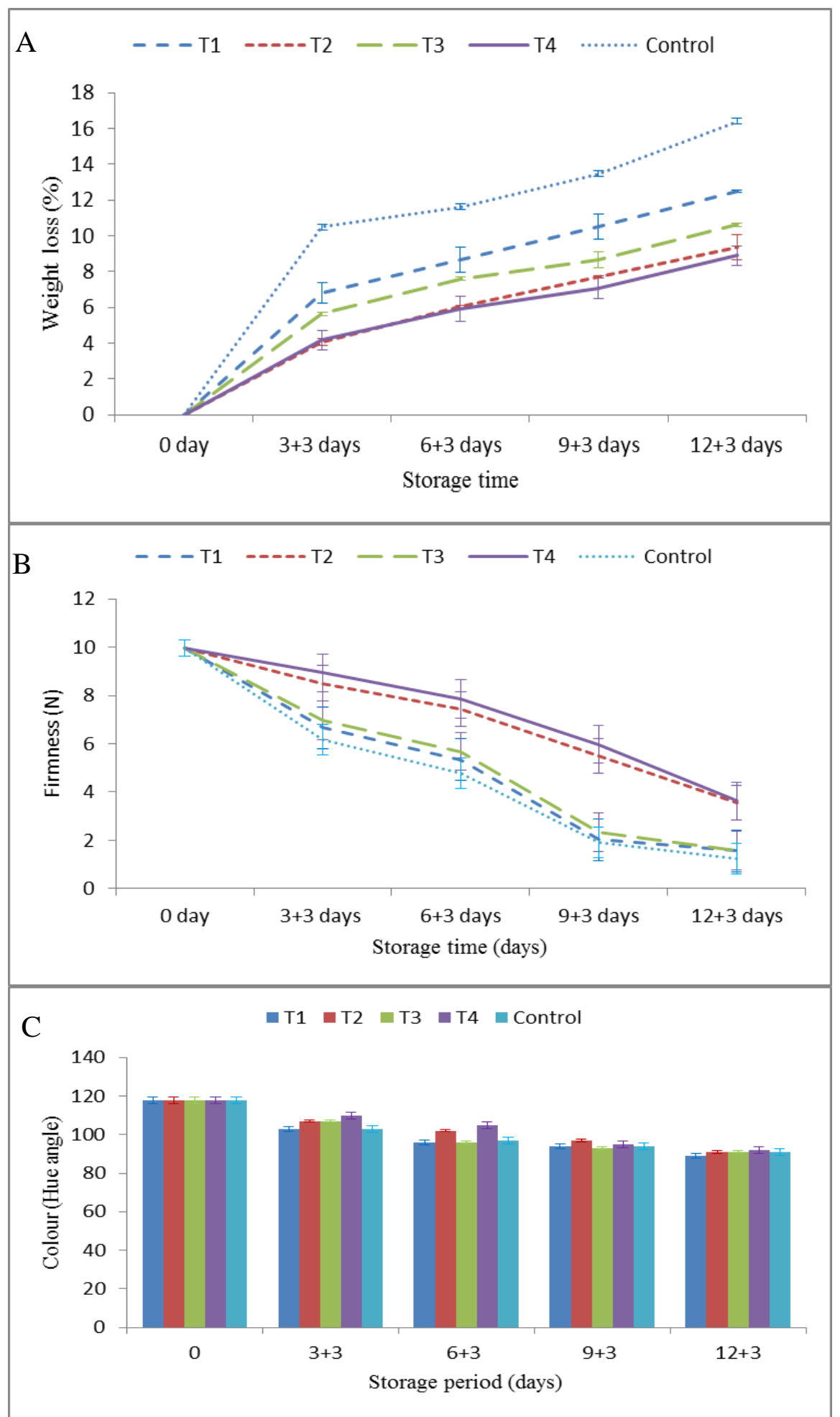


Fig.2 Impact of salicylic acid treatments on A) Respiration rate and B) Ethylene evolution rate of guava cv. Lalit during storage at $10^{\circ} \mathrm{C}$ followed by transfer to ambient conditions for 3 days $\left(\mathrm{T}_{1^{-}}\right.$ SA@1 mM, T2-SA@2 mM, T3-SSA@1 mM, T4-SA@ 2 mM and control). Data are the mean $\pm \mathrm{SE}$ of three replications $(\mathrm{n}=3)$

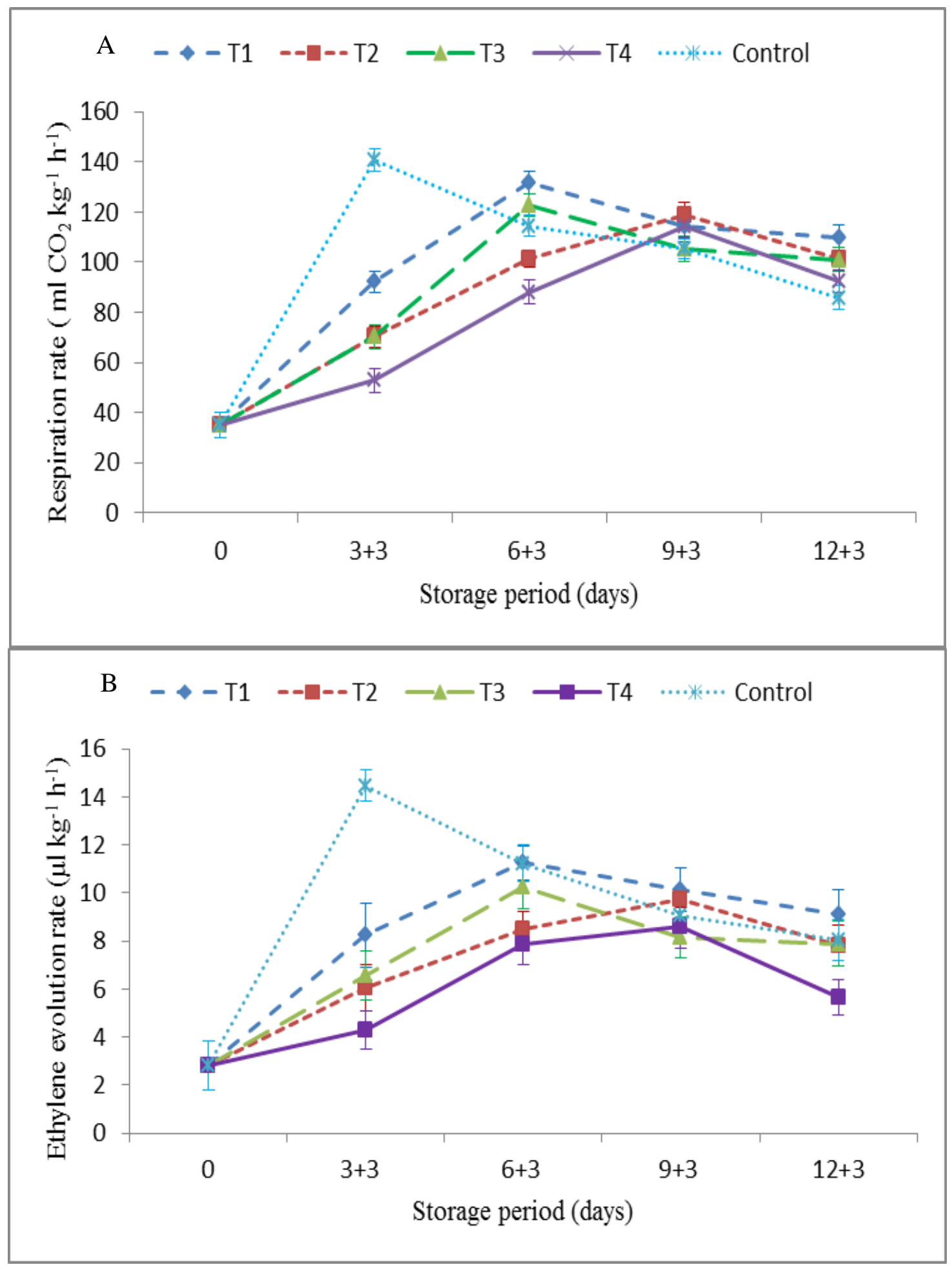


Fig.3 Influence of salicylic acid treatments on A) TSS, B) ascorbic acid content and C) total phenolic content of guava cv. Lalit during storage at $10^{\circ} \mathrm{C}$ followed by transfer ambient conditions for 3 days $\left(\mathrm{T}_{1}\right.$-SA @ 1 mM, T2-SA @ 2 mM, T 3 -SSA @ 1 mM, T 4 -SA @ 2 mM and control). Data are the mean $\pm \mathrm{SE}$ of three replicate determination $(\mathrm{n}=3)$

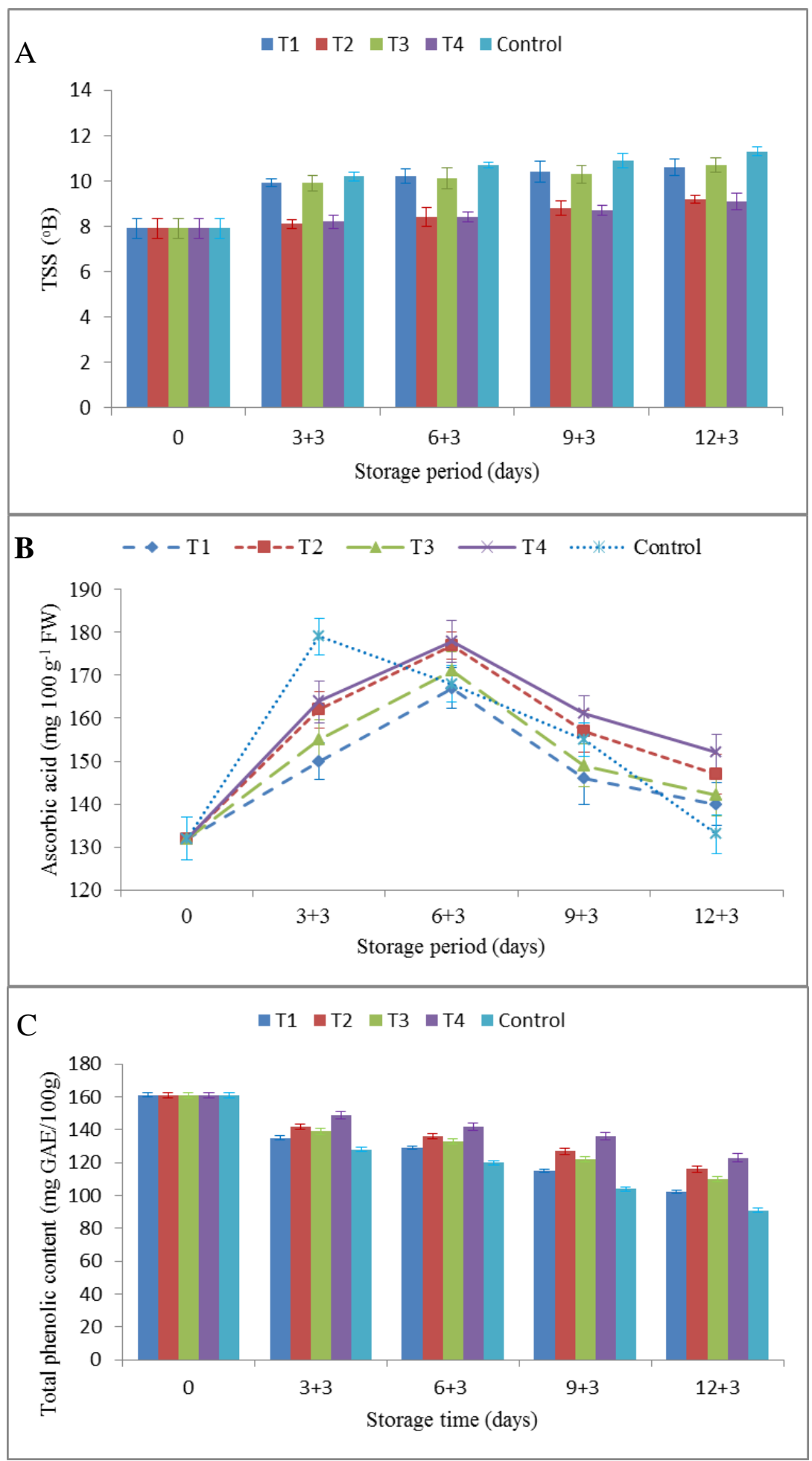


Similar results have been reported earlier by Aghdam et al., (2009) in peach and Sahar and Wahab (2015) in apricot.

In our study, we observed that ascorbic acid content in untreated guava fruits increased up to $3+3$ days of storage but thereafter it showed a declining trend but SA or SSA treated fruits showed an increase in ascorbic acid up to $6+3 \mathrm{~d}$ of storage (Fig. 3B). However, at the end of storage, SSA or SA at $2 \mathrm{mM}$ concentration exhibited higher ascorbic acid content. Increase in ascorbic acid content in guava fruit is thought to be an indication that the fruit is still undergoing ripening, while a decrease indicates onset of senescence (Gonzalez-Aguilar et al., 2004). This delay in attaining maximum ascorbic acid content indicates that ripening process might have been delayed by SA and SAA in the treated guava fruits. In an earlier study, Tareen et al., (2012) had also reported higher retention of ascorbic acid in peach fruits treated with salicylic acid.

There was a gradual decrease in total phenolic content with the progress in storage period (Fig. 3C). However, the decline was at a slower rate in fruits treated with SA or SSA as compared to untreated fruits. Significantly higher phenolic content was recorded in 2 $\mathrm{mM}$ SA and SSA treated fruits while it was lowest in untreated fruits at the end of the storage. Reduced loss of phenols in salicylic acid treated fruits may be due to delayed oxidation of phenolic substances by polyphenol oxidase (PPO). Similar findings were reported earlier by Khademi and Ershadi (2013) in peach and Sahar and Wahab (2015) in apricot.

This study revealed that postharvest application of salicylic acid (SA or SSA @ 2 $\mathrm{mM}$ ) was effective in reducing loss in weight, loss of firmness, colour change and influenced respiration rate and ethylene production rate, which helped in improving shelf-life and maintained the quality of guava fruits during storage.

\section{References}

Antala D K, Varshney A K, Davaraand P R and Sangani V P. 2015. Modified atmosphere packaging of guava fruit. Packaging Technology and Science 28: 557-64.

Asghari M and Aghdam M S. 2010. Impact of salicylic acid on post-harvest physiology of horticultural crops. Trends in Food Science and Technology 21: 502-09.

Barman K and Asrey R. 2014. Salicylic acid pre-treatment alleviates chilling injury, preserves bioactive compounds and enhances shelf life of mango fruit during cold storage. Journal of Scientific and Industrial Research 73: 713-18.

Bashir H A and Abu-Goukh A A. 2003. Compositional changes during guava fruit ripening. Food Chemistry 80: 55763.

Bassetto E, Jacomino A P, Pinheiro A L and Kluge R A. 2005. Delay of ripening of 'Pedro Sato' guava with 1methylcyclopropene. Postharvest Biology and Technology 35: 303- 08.

Gonzalez-Aguilar G A, Tiznado-Hernandez M E, Zavaleta-Gatica R and Mart' 1nezTellez MA. 2004. Methyl jasmonate treatments reduce chilling injury and activate the defense response of guava fruits. Biochemical and Biophysical Research Communications 313: 694701 (2004).

Han T and Li L P. 1997. Physiological effect of salicylic acid on storage of apple in short period. Plant Physiology Communications 33: 347-48. 
Leslie C A and Romani R J. 1988. Inhibition of ethylene biosynthesis by salicylic acid. Plant Physiology 88: 833-37.

Lo'ay A A and El Khateeb A Y. 2011. Delaying guava ripening by exogenous salicylic acid. International Journal of Plant Production 2: 715-24.

NHB. 2015. National Horticulture Database. http://nhb.gov.in/areapro/NHB_Database_2015.pdf.

Panse V G and Sukhatme P V. 1984. Statistical Methods for Agricultural Workers (3rd edn.), Indian Council of Agricultural Research, New Delhi.

Ranganna S. 1999. Handbook of analysis and quality control for fruits and vegetable products. $3^{\text {rd }}$ edition. Tata McGraw-Hill Publishing Company Ltd., New Delhi.

Razavi F, Hajilou J, Dehgan G, Nagshi, R, Hassani, N R B and Turchi M. 2014. Enhancement of postharvest quality of peach fruit by salicylic acid treatment. International Journal of Biosciences. 4: $177-184$.

Sahar M and Wahab A E. 2015. Apricot Postharvest Fruit Quality, Storability and Marketing in Response to Pre harvest Application. Middle East Journal of Agriculture Research. 4: $347-358$
Singh S P and Pal R K. 2008. Controlled atmosphere storage of guava (Psidium guajava L.) fruit. Postharvest Biology and Technology 47: 296-306.

Singleton, V L and Rossi, J A. 1965. Colorimetry of total phenolics with phosphomolybdic-phosphotungstic acid reagents. American Journal of Enology and Viticulture 16: 144-58.

Tareen M J, Abbasi N A and Hafiz I A. 2012. Postharvest application of salicylic acid enhanced antioxidant enzyme activity and maintained quality of peach cv. 'Flordakin' fruit during storage. Scientia Horticulturae 142: 221-28.

Zhang Y, Chen K S, Zhang S L and Ferguson I. 2003. The role of salicylic acid in postharvest ripening of kiwifruit. Postharvest Biology and Technology 28: 67-74.

Zhu F, Chen J, Xiao X, Zhang M, Yun Z, Zeng Y, Xu J, Cheng Y and Deng X. 2016. Salicylic acid treatment reduces the rot of postharvest citrus fruit by inducing the accumulation of $\mathrm{H}_{2} \mathrm{O}_{2}$, primary metabolites and lipophilic polymethoxylated flavones. Food Chemistry 207: 68-74.

\section{How to cite this article:}

Janagam Venu Madhav, Shruti Sethi, R.R. Sharma and Nagaraja, A. 2018. Impact of Salicylic Acid Treatments on Storage Quality of Guava Fruits cv. Lalit during Storage. Int.J.Curr.Microbiol.App.Sci. 7(09): 2390-2397. doi: https://doi.org/10.20546/ijcmas.2018.709.297 